\title{
Small Business Technology Transfer Research
}

National Cancer Institute

\section{Source}

National Cancer Institute. Small Business Technology Transfer Research. NCI

Thesaurus. Code C19049.

A government-wide program that promotes technology transfer by helping investigators form partnerships between the private and public sectors. It differs from SBIR in being somewhat less restrictive in the level of activity permitted for academic institutions. The STTR program is a set-aside program designed to support innovative research -- that has the potential for commercialization of the subject of the research --conducted cooperatively by a small business concern and a research institution. Innovation and the potential for commercialization are two of the review criteria considered in the scientific and technical merit evaluation process. At least 40 percent of the research project is to be conducted by the small business concern and at least 30 percent of the work is to be conducted by the single, "partnering" research institution. 